\title{
Fatores determinantes para a seleção de empresas-modelo para um guia brasileiro de sustentabilidade
}

Determining factors for the selection of model-companies for a Brazilian sustainability guide

\author{
Bárbara Quatrin Tiellet da Silva', Angelica Peripolli", \\ Saymon Ricardo de Oliveira Sousa"', Roselaine Ruviaro Zanini'v
}

\begin{abstract}
RESUMO
Essa pesquisa tem como objetivo identificar quais variáveis estão associadas à seleção de empresas para o Guia de Sustentabilidade da Revista Exame. Foram analisadas as variáveis: tamanho da empresa, setor de atividade, localização, participação na bolsa de valores, controle acionário, propriedade e participação no Índice de Sustentabilidade Empresarial (ISE). Utilizou-se a técnica de regressão logística múltipla para desenvolver o modelo em relação aos fatores de risco associados à seleção das empresas. Mostraram-se estatisticamente significativas as covariáveis: setor de atividade $(p<0,001)$, controle acionário $(p=0,035)$ e participação no ISE $(p<0,001)$. Os resultados mostram que as empresas cujas atividades utilizam diretamente recursos naturais e/ou modificam o ambiente, que estão em ambientes mais internacionalizados, controladas total ou parcialmente por países estrangeiros e que fazem parte do ISE, tem maior probabilidade de serem selecionadas. Esse trabalho apresenta uma contribuição original para a literatura, por ampliar o entendimento das características empresariais que podem influenciar práticas de Responsabilidade Social Corporativa e Sustentabilidade Empresarial no Brasil.
\end{abstract}

Palavras-chave: Sustentabilidade empresarial. Fatores de risco. Regressão logística múltipla

\begin{abstract}
This research aims to identify which variables are associated with the selection of companies for the Exame Magazine Sustainability Guide. The following variables were analyzed: size of the company, sector of activity, location, participation in the stock exchange, stock control, ownership and participation in the Corporate Sustainability Index (ISE). Multiple logistic regression was used to develop the model in relation to the risk factors associated to the selection of companies. The covariates were statistically significant: activity sector $(p<0.001)$, stock control $(p=0.035)$ and participation in ISE ( $p$ $<0.001$ ). The results show that companies whose activities directly use natural resources and/or modify the environment, which are in more internationalized environments, totally or partially controlled by foreign countries and which are part of ISE, are more likely to be selected. This paper presents an original contribution to the literature, since it broadens the understanding of business characteristics that can influence practices of Corporate Social Responsibility and Corporate Sustainability in Brazil.
\end{abstract}

Keywords: Corporate Sustainability. Risk Factors. Multiple Logistic Regression

\footnotetext{
'Universidade Federal de Santa Maria, Brasil; e-mail: barbara.silva@proplan.ufrgs.br;

" Universidade Federal de Santa Maria. Brasil. e-mail: angelicaperipolli@gmail.com;

III Universidade Federal de Santa Maria, Brasil; e-mail: saymon.ricardo.sousa@gmail.com;

Iv Universidade Federal de Santa Maria. Brasil. e-mail: rrzanini63@gmail.com
} 


\section{INTRODUÇÃO}

Nos últimos anos, os desastres ambientais, as mudanças climáticas, o esgotamento de recursos naturais, o agravamento das desigualdades sociais em conjunto com uma crescente conscientização das pessoas sobre tais problemas, fizeram com que a percepção sobre o papel das empresas mudasse. Além da geração de lucros e empregos, as empresas passaram a ser cobradas por sua responsabilidade com o ambiente, com o desenvolvimento sustentável e com a sociedade impactados por elas (CONFALONIERI; MARINHO, 2007; GONZALEZ; ANDRADE, 2015; OLIVEIRA; SILVA; CARDOSO; OLIVEIRA; CASTRO; PINTO, 2018). Assim sendo, algumas organizações começaram a adaptar-se a essas cobranças e valorizar as questões ambientais, sociais e de sustentabilidade. Outras, simplesmente ignoraram tais cobranças, alegando que investir nessas questões vai contra o principal objetivo de uma empresa, que é a geração de lucro (OLIVEIRA; ALMEIDA; ROCHA; TORTATO; SILVA, 2015; IRIGARAY; VERGARA; ARAÚJO, 2017).

Apesar de nem todas as organizações estarem conscientes de suas responsabilidades além das financeiras, é possível perceber e inegável, que a sociedade contemporânea não espera apenas lucros e geração de empregos por parte das empresas, mas que invistam em preservação e reparo aos danos causados ao meio ambiente, que assegurem boas condições de trabalho, que respeitem e valorizem fornecedores e consumidores, e que contribuam para o bem-estar das comunidades onde estão inseridas e da sociedade como um todo.

Essas novas cobranças podem ser expressas por meio dos conceitos de Responsabilidade Social Corporativa (RSC) e Sustentabilidade Empresarial (SE). De acordo com Carroll (1979), RSC supõe que as organizações possuem não apenas obrigações econômicas e legais, mas também responsabilidades para com a sociedade. Tenório (2015) reitera que a responsabilidade social nasce de um compromisso da organização com a sociedade, ampliando sua participação para além da geração de empregos, impostos e lucros. Já a SE representa a expansão do modelo de negócios tradicional para um modelo que considere, além da performance financeira, a performance ambiental e social da empresa nas interações com os 
stakeholders (funcionários, fornecedores, clientes, consumidores, comunidade, organizações da sociedade civil, governo, enfim, todos que possam ter interesses e relacionamentos com a organização). Nesse sentido, Wajnberg e Lemme (2009) contribuem para a compreensão do conceito de SE ao afirmarem que está associado ao "triple bottom line", conceito proposto por Elkington (1998), que defende que a SE apoia-se na prosperidade econômica, na qualidade ambiental e na justiça social.

No Brasil, a partir de 1990 houve uma tendência de os investidores procurarem por empresas socialmente responsáveis, sustentáveis e rentáveis para investirem (Bolsa de Valores, Mercadorias e Futuros, 2013). Também, a maior atenção dos consumidores e as preocupações das empresas com RSC e SE, fizeram com que metodologias fossem desenvolvidas para distinguir e valorizar as empresas que investem nessas questões. Destacam-se o Guia de Sustentabilidade da Revista Exame e o Índice de Sustentabilidade Empresarial (ISE) da Bolsa de Mercadorias \& Futuros (BM\&F) e Bolsa de Valores de São Paulo (BOVESPA), elaborados no Centro de Estudos em Sustentabilidade da Fundação Getúlio Vargas (Gvces), referência no desenvolvimento de estratégias, políticas e ferramentas de gestão públicas e empresariais em sustentabilidade. Pesquisas científicas mostram que empresas que aderem a indicadores de sustentabilidade são influenciadas por variáveis como o tamanho da empresa, setor de atividade, concentração acionária, localização, dentre outras (GOLDNER; TEIXEIRA; NOSSA; GALDI, 2010; VEIGA, 2010).

Assim sendo, no presente estudo utilizou-se a técnica de regressão logística com o objetivo de verificar, entre as 500 maiores empresas brasileiras de 2012, a relação entre tamanho da empresa, setor de atividade, localização, participação na bolsa de valores, controle acionário, propriedade e participação no Índice de Sustentabilidade Empresarial com a seleção dessas empresas para o Guia de Sustentabilidade da Revista Exame. A pesquisa foi construída tendo como alicerce a questão: quais são os fatores que influenciam a seleção de empresas modelo no Brasil tendo em vista a Responsabilidade Social Corporativa e Sustentabilidade Empresarial? 
Este estudo apresenta uma contribuição original à literatura, pela discussão sobre RSC e SE no âmbito empresarial e sobre as variáveis que influenciam a escolha das empresas modelo em responsabilidade corporativa e sustentabilidade no país. Pretende-se contribuir com o entendimento sobre a aplicação da técnica de regressão logística, uma vez que esta técnica tem despertado interesse em diversas áreas do conhecimento.

\section{REFERENCIAL TEÓRICO}

Neste tópico são apresentados os conceitos sobre Responsabilidade Social Corporativa e Sustentabilidade Empresarial, para que se possa compreender a origem e importância dos índices e guias que distinguem empresas com preocupações além das financeiras.

\subsection{Responsabilidade Social Corporativa e Sustentabilidade Empresarial}

Com os avanços tecnológicos e o crescente aumento populacional decorrentes da Revolução Industrial, a atividade humana passou a causar mais impactos negativos ao meio ambiente. Desde então, em busca por desenvolvimento e crescimento econômico, as empresas adotaram um ciclo produtivo de extração de recursos e insumos do meio ambiente, e "devolução" de resíduos e poluentes em grandes quantidades, acarretando poluição ambiental e esgotamento dos recursos naturais (BUENO; SALVADOR, 2012).

Pode-se dizer que, até o início da década de 1970, o pensamento mundial dominante era o de que o meio ambiente seria fonte inesgotável de recursos. Mas fenômenos como secas, chuva ácida e a inversão térmica fizeram com que essa visão ambiental do mundo começasse a ser questionada (SOARES; NAVARRO; FERREIRA, 2004). Esse panorama fez com que o papel das empresas também começasse a ser questionado, em relação à responsabilidade delas para com a sociedade e o meio ambiente e com um desenvolvimento sustentável do planeta.

Em épocas passadas, acidentes ambientais, trabalho infantil, demissões em massa recebiam pouca atenção da mídia e dos consumidores. Questões que outrora não eram consideradas no processo decisório e irrelevantes para o sucesso da 
empresa passaram a ser cruciais (MACEDO; SOUSA; SOUSA, 2008). Assim, um desempenho social inadequado e a falta de políticas de cunho social e ambiental passaram a ter impactos negativos, acarretando prejuízos materiais e morais. Diante disso, é possível dizer que estamos na era da responsabilidade, conjuntura em que as empresas precisam aceitar e se comprometer com as consequências de suas decisões e ações (MACEDO; SOUSA; SOUSA, 2008; ALIGLERI; ALIGLERI; KRUGLIANSKAS, 2009).

A gestão empresarial que dominou os últimos anos respondeu unicamente aos interesses dos acionistas, ou shareholders, mostrando-se insuficiente nesse novo contexto, onde as empresas são consideradas responsáveis não só por suas atividades, mas também pelas consequências para os seus públicos. Nesse sentido, existe um debate sobre a função-objetivo das empresas, que é a visão dos shareholders em contraposição à dos stakeholders (ALIGLERI; ALIGLERI; KRUGLIANSKAS, 2009; SILVEIRA; YOSHINAGA; BORBA, 2005; BOAVENTURA; CARDOSO; SILVA; SILVA, 2009).

Por um lado, existe o argumento de que a atividade de uma empresa possui uma dimensão ética, além da econômica e da legal, e que é amplamente aceita. Entretanto, não existe um consenso sobre o que representa essa dimensão e sobre quem deve se responsabilizar por ela (MACHADO FILHO; ZYLBERSZTAJN, 2004; ANDRADE; MOREIRA; PEDROSA, 2012).

Assim, alguns defendem a teoria dos shareholders, denominada teoria da firma, que surgiu com a ciência econômica, no século XVIII, com Adam Smith e autores como Coase (1937) que contribuíram para difundi-la, na qual as decisões dos gestores devem focar, exclusivamente, na dimensão econômica da empresa, maximizando a riqueza dos acionistas (ANDRADE; MOREIRA; PEDROSA, 2012; ANDRADE; BRESSAN; IQUIAPAZA; MOREIRA, 2013).

Entretanto, há outro grupo que defende a teoria de que empregados, fornecedores, clientes, e comunidade em geral, isto é, os stakeholders, também são afetados pela empresa e que as decisões dos gestores devem compreender seus diferentes objetivos. Ademais, autores que defendem esta teoria (DONALDSON; 
PRESTON, 1995; CAMPBELL, 1997) argumentam que os gestores devem entender que as empresas não sobrevivem apenas com os shareholders, mas sim agregando valor aos stakeholders.

Essa perspectiva da visão dos stakeholders implica a organização sentir-se responsável por suas ações perante a todos que possam considerar-se parte interessada nas atividades da empresa. A visão de responsabilidade empresarial expandiu-se à medida que as empresas aumentaram seu poder de atuação na sociedade, adquirindo um papel mais significativo no contexto da globalização (ALIGLERI; ALIGLERI; KRUGLIANSKAS, 2009).

Assim, conceitos de Responsabilidade Social Corporativa e Sustentabilidade Empresarial ganham notoriedade e se consolidam cada vez mais. De acordo com Carroll (1979), o conceito de Responsabilidade Social Corporativa é amplo, além das preocupações puramente econômicas e devendo incluir os seguintes aspectos de responsabilidade: (i) econômica: como base, pois uma empresa não existe sem lucro; (ii) legal: pois espera-se que as empresas conciliem seus objetivos econômicos com as normas e leis vigentes em seu país; e (iii) discricionariedade e filantropia: espera-se que a empresa tenha desejo voluntário em contribuir com a sociedade, sem ser forçada pela ética, leis e interesses econômicos.

McWilliams e Siegel (2000) concordam com Carroll (1979) ao sugerir que a RSC refere-se a ações voltadas ao bem-estar social, para além da competitividade e do cumprimento de leis, assumindo um caráter de voluntarismo e filantropia. Já para Melo e Froes (2001), o conceito de Responsabilidade Social está associado a um compromisso da empresa em relação à sociedade e à humanidade em geral, sendo uma forma de prestação de contas do desempenho da empresa, baseada na apropriação e uso de recursos que originalmente não pertenciam à organização.

A maioria dos conceitos sobre RSC aborda a ideia de ações para a sociedade em geral. Amplia a preocupação "para dentro", com o público interno da empresa, ao afirmar que ao adicionar às competências básicas a conduta ética e socialmente responsável, as organizações conquistam o respeito das comunidades, o engajamento de seus colaboradores e a preferência dos consumidores. O conceito de 
RSC compreende padrões de boas práticas que podem ser aplicados a todos os tipos de organizações. E também, cada vez mais empresas procuram investir em projetos e divulgar suas ações de RSC, pois, afinal, ser reconhecida como um empresa responsável e preocupada com seus stakeholders e com a sociedade em geral contribui para uma imagem e desempenho positivos, resultando em confiança e credibilidade para a organização (MACEDO; SOUSA; SOUSA, 2008).

As organizações desejam mostrar que são intocáveis, alinhadas com a moral e sintonizadas com os costumes vigentes. Assim, surgem os debates sobre a sustentabilidade dos negócios e o conceito de Sustentabilidade Empresarial que, é a capacidade de a empresa alinhar desempenho financeiro com atuação social e equilíbrio ambiental (REZENDE; SANTOS, 2006).

A RSC e SE são, frequentemente, considerados sinônimos. Entretanto, sustentabilidade pode ser a capacidade de se auto-sustentar, se auto-manter por um período indeterminado de tempo, apesar de imprevistos que possam ocorrer. Ademais, pode-se considerar sustentável a sociedade que não coloca em risco os recursos naturais como ar, água, solo, vida animal e vegetal, dos quais depende (ANDRADE; MOREIRA; PEDROSA, 2012).

Já o conceito de Sustentabilidade Empresarial está associado às atividades empresariais que demostram a inclusão de aspectos sociais e ambientais nas suas atividades e nas interações com stakeholders Van Marrewijk (2003). Tendo em vista a inclusão dos aspectos social e ambiental ao conceito de $\mathrm{SE}$, um conceito que contribui para o seu entendimento é o "triple bottom line", ou "tripé da sustentabilidade", proposto em 1994 por John Elkington, sociólogo inglês, com a ideia de que as empresas deveriam medir o valor que geram, ou destroem, nas dimensões econômica, social e ambiental.

Desta forma, para criar vantagens competitivas sustentáveis de longo prazo, as empresas precisam contemplar questões econômicas, sociais e ambientais. Dessa forma, seria possível atingir a sustentabilidade econômica, com empresas lucrativas e geradoras de valor; a sustentabilidade social, ao estimular cultura, educação, lazer, 
justiça; e a sustentabilidade ecológica, ao manter preservados e vivos os ecossistemas (VALLANI; RIBEIRÃO, 2006).

Assim sendo, cabe destacar que, quando se fala em SE, não se pode separar as questões econômicas, sociais e ambientais, sendo que o conceito "triple bottom line" propõem uma visão mais ampla sobre sustentabilidade, muito além da econômica, implicando que uma organização sustentável atende os interesses econômicos, sociais e ambientais de todos os stakeholders afetados por ela (ARAÚJO; BUENO; SOUSA; MENDONÇA, 2006).

Apesar das diferenças conceituais entre RSC e SE, sendo a SE a inclusão de critérios sociais e ambientais no processo decisório da empresa, em uma relação de integração e não de conflitos e a RSC referir-se à predisposição da empresa em assumir responsabilidades sobre os impactos causados na sociedade (CALDELLI; PARMIGIANI, 2004). Os dois conceitos refletem uma mudança no pensamento e comportamento das empresas que passam a se preocupar com o impacto de suas atividades, e no comportamento dos consumidores que passam a valorizá-las em comparação com outras que não têm esse tipo de postura.

Com a evolução desses conceitos percebe-se, também, uma maior atenção e empenho das empresas com o seu papel para além do econômico, com uma visão também voltada para os stakeholders; uma maior atenção e cobrança por parte dos consumidores; e, a partir da década 1990 no Brasil, uma tendência de os investidores procurarem por empresas socialmente responsáveis, sustentáveis e rentáveis para investirem (BOLSA DE VALORES, MERCADORIAS E FUTUROS, 2013).

Tais mudanças contribuíram para que metodologias fossem desenvolvidas, sendo que, no Brasil, destacam-se o Guia de Sustentabilidade da Revista Exame e o Índice de Sustentabilidade Empresarial (ISE), que são apresentados a seguir.

\subsubsection{Guia de Sustentabilidade}

Desde os anos 2000, a Revista Exame realiza o maior levantamento sobre práticas de responsabilidade corporativa no Brasil: de 2000 a 2006 o Guia EXAME de Boa Cidadania Corporativa e, desde 2007, o Guia EXAME de Sustentabilidade, cuja 
metodologia foi desenvolvida pelo Centro de Estudos em Sustentabilidade da Fundação Getúlio Vargas (GVces). Aberto a todas as empresas instaladas no país, privadas ou públicas, de capital aberto ou fechado, grandes, médias ou pequenas, o Guia apresenta a disposição dessas empresas a fortalecer suas estratégias de sustentabilidade.

Em 2012, 170 empresas inscreveram-se para avaliação, que inicia com um questionário disponível no Portal Exame, sendo que 123 passaram para etapa seguinte ao responderam a todas as perguntas. As respostas foram estatisticamente analisadas e 42 foram selecionadas e apresentadas ao conselho deliberativo que, considerando as pontuações e checagem da veracidade das informações, definiu a lista das 21 empresas modelo.

\subsection{2 Índice de Sustentabilidade Empresarial}

O Índice de Sustentabilidade Empresarial (ISE) é um índice que mede o retorno total de uma carteira teórica composta por ações de empresas com reconhecido comprometimento com a responsabilidade social e a sustentabilidade empresarial, sendo uma ferramenta para análise comparativa da performance das empresas listadas na BM\&FBOVESPA. Tal índice tem como missão: "Induzir as empresas a adotarem as melhores práticas de sustentabilidade empresarial e apoiar os investidores na tomada de decisão de investimentos socialmente responsáveis.", propiciando um ambiente de investimento compatível com as demandas de desenvolvimento sustentável da sociedade contemporânea (BOLSA DE VALORES, MERCADORIAS E FUTUROS, 2013).

No Brasil, essas demandas por desenvolvimento sustentável estão em evidência e há expectativa de que cresçam e se consolidem. Atentas a isso, a BM\&FBOVESPA e um conjunto de instituições, entre Associações e ONGs, uniram-se para criar um índice de ações que fosse referencial para os investimentos socialmente responsáveis. Lançado em 2005, o ISE é o quarto índice de sustentabilidade do mundo, sendo antecedido pelo Dow Jones Sustainability Index (DJSI) da bolsa de Nova Iorque em 1999, pelo FTSE4Good da bolsa de Londres, em 2001, e pelo JSE de 
Joanesburgo, África do Sul, em 2003, e diferencia as empresas para investidores com outras preocupações além do retorno financeiro. Para integrar a carteira do ISE, a empresa deve: apresentar liquidez, sendo emissora de uma das 200 ações mais líquidas da BM\&FBOVESPA; ter sido negociada em pelo menos $50 \%$ dos pregões ocorridos nos 12 meses anteriores ao início do processo de reavaliação e atender aos critérios de sustentabilidade do Conselho Deliberativo do ISE (BOLSA DE VALORES, MERCADORIAS E FUTUROS, 2013).

Conforme mencionado anteriormente, sua metodologia também foi desenvolvida pelo GVces e tem como base um questionário e avaliação documental, combinando análise quantitativa: pontuação obtida nas respostas ao questionário e análise qualitativa: avaliação da documentação enviada para comprovação das respostas. As respostas das companhias são analisadas por uma ferramenta estatística chamada "análise de clusters", que identifica grupos de empresas com desempenhos similares e aponta o grupo com melhor desempenho geral. Após aprovação do Conselho, as empresas pertencentes a este grupo (no máximo 40 empresas) passam a compor a carteira final do ISE, que tem uma revisão anual (BOLSA DE VALORES, MERCADORIAS E FUTUROS, 2013).

A Carteira 2012/2013 foi anunciada no dia 29 de novembro de 2012 e vigorou de 07 de janeiro de 2013 a 03 de janeiro de 2014. Reuniu 51 ações de 37 companhias, que representam 16 setores e somam $\mathrm{R} \$ 1,07$ trilhão em valor de mercado.

\section{METODOLOGIA}

Uma vez que o presente estudo buscou verificar as variáveis que influenciam a seleção de empresas para o Guia da Revista Exame e, tendo em vista que, das 21 empresas modelo de 2012, 12 estavam presentes na listagem "Exame Melhores e Maiores", composta pelas 500 maiores empresas brasileiras de 2012, optou-se por utilizar essa listagem como base de dados, a partir da ferramenta "Melhores e Maiores". Assim, a amostragem é considerada não probabilística, pois parte de um universo restrito de empresas, escolhidas por conveniência. 
Inicialmente foram selecionadas as 500 maiores empresas brasileiras de 2012, sendo 24 destas listadas no Guia diretamente ou pertencentes a um grupo selecionado para o Guia. Entretanto, por falta de informações, 6 tiveram de ser excluídas da análise, restando 494 empresas, mas permanecendo as 24 pertencentes ao Guia. Considerando as informações obtidas, as variáveis foram organizadas conforme o Quadro 1.

Quadro 1 - Variáveis consideradas para construção do modelo de regressão logística múltiplo

\begin{tabular}{|c|c|c|c|}
\hline Variável & Denominação & Fonte & Codificação \\
\hline SUS & $\begin{array}{l}\text { Guia Exame } \\
\text { de Sustentabilidade }\end{array}$ & $\begin{array}{l}\text { Guia Exame de } \\
\text { Sustentabilidade } 2012\end{array}$ & $\begin{array}{l}0 \text { - Não } \\
1 \text { - Sim }\end{array}$ \\
\hline TAM & Tamanho da empresa & $\begin{array}{l}\text { Revista "Exame Melhores } \\
\text { e Maiores" de } 2012\end{array}$ & $\begin{array}{l}0 \text { - Outras } \\
1-100 \text { maiores }\end{array}$ \\
\hline SET & Setor de atividade & $\begin{array}{l}\text { Revista "Exame Melhores } \\
\text { e Maiores" de } 2012\end{array}$ & $\begin{array}{l}0 \text { - Outros } \\
1 \text { - Recursos Naturais }\end{array}$ \\
\hline LOC & Localização & $\begin{array}{l}\text { Revista "Exame Melhores } \\
\text { e Maiores" de } 2012\end{array}$ & $\begin{array}{l}0 \text { - Sudeste } \\
1 \text { - Sul } \\
2 \text { - Centro-oeste } \\
3 \text { - Norte e Nordeste }\end{array}$ \\
\hline BOLSA & $\begin{array}{l}\text { Participação na } \\
\text { BM\&FBOVESPA }\end{array}$ & $\begin{array}{l}\text { Revista "Exame Melhores } \\
\text { e Maiores" de } 2012\end{array}$ & $\begin{array}{l}0 \text { - Não } \\
1 \text { - Sim } \\
\end{array}$ \\
\hline CONTR & Controle acionário & $\begin{array}{l}\text { Revista "Exame Melhores } \\
\text { e Maiores" de } 2012\end{array}$ & $\begin{array}{l}0 \text { - Brasileiro } \\
1 \text { - Estrangeiro e misto }\end{array}$ \\
\hline PROPR & Propriedade & $\begin{array}{l}\text { Revista "Exame Melhores } \\
\text { e Maiores" de } 2012\end{array}$ & $\begin{array}{l}0 \text { - Estatal } \\
1 \text { - Privada }\end{array}$ \\
\hline ISE & $\begin{array}{l}\text { Índice de Sustentabilidade } \\
\text { Empresarial }\end{array}$ & Carteira 2012/2013 do ISE & $\begin{array}{l}0 \text { - Não } \\
1-\operatorname{Sim}\end{array}$ \\
\hline
\end{tabular}

O tamanho da empresa, originado a partir das vendas anuais, foi primeiramente utilizado como uma variável contínua, sendo reclassificado em função das 100 maiores empresas do ano (fato destacado pela revista). Os 21 setores de atividade foram classificados como setores que utilizam diretamente recursos naturais, renováveis ou não, e demais setores. Os setores classificados como recursos naturais foram energia, mineração, papel e celulose, produção agropecuária, química e petroquímica e siderurgia e metalurgia. 
O uso da variável localização permite classificar as empresas entre as regiões do país, entretanto, como havia poucas empresas representantes da região Norte, optou-se por juntá-la à região Nordeste em uma categoria só, com vistas a não prejudicar a análise pela pouca frequência na região Norte. A variável participação na BM\&FBOVESPA possibilita identificar se as empresas tem ou não ações na bolsa.

O controle acionário possibilita classificá-las como tendo controle brasileiro ou estrangeiro e misto (brasileiro e estrangeiro conjuntamente). Por sua vez, a propriedade permite dividir as empresas em privadas e estatais e, o Índice de Sustentabilidade Empresarial, se refere às empresas pertencentes ou não ao índice e às empresas que fazem parte de um grupo que esteja listado no ISE.

Para definir o modelo mais adequado foi utilizada a Regressão Logística, e as análises foram feitas com o aplicativo SPSS (PASW Statistics18), da seguinte maneira:

1) análise univariada: realizou-se a análise de regressão logística univariada (método enter) considerando cada uma das variáveis independentes e aquelas com p-valor $\leq 0,25$ foram incluídas no modelo múltiplo. Segundo Hosmer e Lemeshow (1989), toda covariável nesta situação deve ser considerada candidata ao modelo múltiplo, junto com todas as variáveis de importância conhecida. Ainda, nesta etapa, foram estimadas as razões de chance brutas ( $\left.\mathrm{OR}_{\text {bruto }}\right)$ e os respectivos intervalos de 95\% de confiança (IC 95\%);

2) análise de regressão logística múltipla: as variáveis selecionadas anteriormente foram incluídas, simultaneamente, no modelo. Utilizou-se o método enter, estabeleceu-se um IC 95\% para a ORajustado, admitindo-se tolerância de dois desvios padrão para outliers. As variáveis não significativas foram eliminadas, uma a uma. A cada exclusão o modelo era processado para que os coeficientes fossem reajustados. Foi utilizado o teste da razão de verossimilhança para decidir a permanência das variáveis no modelo e, o teste de Wald, para estabelecer a significância dos coeficientes. Optou-se por excluir uma observação do banco de dados pois apresentava resíduos muito maiores que 2 desvios. Retirando-se essa observação, a análise foi processada novamente. 


\section{APRESENTAÇÃo E ANÁLISE DOS RESULTADOS}

Apesar de não existir um estudo prévio sobre a seleção de empresas para o Guia de Sustentabilidade, pesquisas indicam que empresas que aderem a índices e indicadores de sustentabilidade são influenciadas por algumas variáveis.

Nesse sentido, em estudo sobre a adesão de empresas ao ISE, Goldner, Teixeira, Nossa e Galdi, (2010) testaram: tamanho da empresa, setor de atividade, concentração acionária, localização do controle acionário, emissão de American Depositay Receipts (ADR) e propriedade. Ainda, um estudo sobre os determinantes de investimentos em sustentabilidade empresarial pelas empresas brasileiras de capital aberto, Andrade, Bressan, Iquiapaza e Moreira (2013) analisaram: tamanho da empresa, endividamento, capacidade de financiamento, rentabilidade, inovação e diferenciação de produtos e crise financeira mundial. Com o objetivo de identificar determinantes para a adesão ao ISE, os autores também, testaram: tamanho da empresa, endividamento, capacidade de financiamento, rentabilidade e crescimento das vendas, setor de atividade e crise financeira mundial.

Esses estudos basearam-se no trabalho realizado por Artiach, Lee, Nelson e Walker (2010), que analisaram as variáveis que influenciam as empresas americanas a investirem em sustentabilidade, encontrando associação significativa com o tamanho da empresa, níveis mais elevados de crescimento e maior retorno sobre o patrimônio líquido.

Relativamente ao presente estudo, inicialmente, determinou-se as variáveis candidatas ao modelo múltiplo, sendo as significativas apresentadas na Tabela 1. 
Tabela 1 - Variáveis significativas conforme análise de regressão logística univariada

\begin{tabular}{lccc}
\hline Variáveis & ORbruto & IC 95\% & p-valor \\
\hline Tamanho da empresa & & & \\
\hline Outras & 1 & & \\
100 maiores & 2,533 & $1,074-5,973$ & $0,034^{*}$ \\
\hline Setor de atividade & 1 & & \\
\hline Outros & 6,4 & $2,490-16,451$ & $<0,001^{*}$ \\
Recursos naturais & & & \\
\hline Participação na BM\&FBOVESPA & 1 & & \\
\hline Não & 2,298 & $0,952-5,544$ & $0,064^{*}$ \\
Sim & & & \\
\hline Controle acionário & 1 & & \\
\hline Brasileiro & 2,448 & $1,064-5,631$ & $0,035^{*}$ \\
Estrangeiro e misto & & & \\
\hline ISE & 1 & & \\
\hline Não & 9,096 & $3,827-21,622$ & $<0,001^{*}$ \\
Sim & & & \\
\hline Nota: OR: odds ratio; & & & \\
ORbruto 1 : categoria de referência; & & & \\
IC 95\%: intervalo de confiança de 95\%. & & & \\
* p-valor $\leq 0,25$. & & & \\
\end{tabular}

Dentre aquelas testadas, o tamanho da empresa justifica-se por ser bastante utilizado em estudos sobre os determinantes da sustentabilidade empresarial, principalmente porque grandes empresas são mais visíveis politicamente, sofrem mais pressões dos stakeholders e são mais propensas a criar problemas sociais em função da escala de suas atividades (ARTIACH; LEE; NELSON; WALKER, 2010). Essa, em geral, é medida pelo número de empregados, valor do ativo total, receita de vendas ou de acordo com ranking de periódicos. Assim, esperava-se uma associação significativa entre o tamanho da empresa e a seleção para o Guia de Sustentabilidade, o que foi confirmado na primeira etapa da análise de regressão.

O setor de atividade foi testado tendo em vista as diferenças de impactos gerados sobre o meio ambiente dos vários setores presentes na listagem das 500 maiores empresas. Dierkes e Preston (1977) demonstraram que empresas cujas atividades modificam o ambiente são mais monitoradas em relação ao seu desempenho ambiental. Nesse sentido, esperava-se que os setores que utilizam diretamente recursos naturais estivessem relacionados com a escolha das empresas modelo em sustentabilidade, fato confirmado na regressão univariada. 
A localização foi analisada esperando-se que pudesse haver uma relação significativa entre as empresas localizadas na região Sudeste, região com a maior concentração industrial do país, e seleção para o Guia. Entretanto, essa associação não foi confirmada.

A participação na bolsa de valores BM\&FBOVESPA foi considerada, pois, embora as ações sociais e de sustentabilidade devam ser consideradas como parte da estratégia empresarial, no contexto das empresas de capital aberto, este aspecto torna-se imprescindível, uma vez que devem desenvolver e manter uma imagem fortalecida com vistas a obter melhores resultados no mercado financeiro. Dessa forma, esperava-se encontrar uma associação significativa entre participação na BM\&FBOVESPA e o Guia de Sustentabilidade, o que foi confirmado no resultado da análise univariada.

Ao testar o controle acionário, esperava-se identificar se um controle estrangeiro contribui para as práticas de sustentabilidade, que seriam influenciadas pela cultura e normas ambientais do país de origem do controle. Nesse sentido Braga, Oliveira e Salotti (2010) consideraram a hipótese de que empresas que estão em ambientes mais internacionalizados têm maior propensão a divulgar mais informações ambientais. Mas, o estudo realizado com 108 companhias abertas listadas na BM\&FBOVESPA sugere que não há significância na relação entre o nível de divulgação ambiental e a origem do controle acionário. No entanto, para o presente estudo, o controle acionário apresentou-se significativa na análise univariada.

Relativamente à propriedade, é característica do país a presença do Estado no controle de algumas empresas. De acordo com Neto (2004), as empresas de propriedade privada têm como principal objetivo a maximização de sua riqueza. Por outro lado, as estatais possuem interesses diferentes e encaminham os seus investimentos para suprir algumas necessidades, sejam econômicas ou sociais, atuando como complementares à atividade privada e sem pressão para que maximizem o resultado de suas atividades. Assim sendo, da mesma forma que Nunes, Teixeira e Nossa (2009), esperava-se encontrar uma relação significativa entre 
as empresas estatais e o Guia de Sustentabilidade, o que não foi evidenciado neste estudo.

Por fim, a participação no Índice de Sustentabilidade Empresarial foi testada, pois este índice lista ações de empresas com reconhecido comprometimento com a responsabilidade social e a sustentabilidade empresarial, e cuja metodologia foi elaborada pelo GVces, da mesma forma que o Guia de Sustentabilidade da Revista Exame. Assim sendo, esperava-se encontrar uma associação significativa do Índice com o Guia, o que foi confirmado.

Após a análise univariada, foram testadas as covariáveis significativas $(p \leq 0,25)$ no modelo múltiplo. Em seguida, conforme descrito anteriormente, foram excluídas do modelo, uma a uma, as covariáveis não significativas ( $p$-valor $>0,05$ ), sendo a participação na BM\&FBOVESPA e o tamanho da empresa.

A exclusão da primeira contrariou a suposição de que, por estarem mais expostas e precisarem manter uma postura ética e social para obter melhores resultados no mercado financeiro, as empresas com ações na BM\&FBOVESPA seriam mais propensas a desenvolver práticas de RSC e SE, tendo maiores chances de ser selecionadas para o Guia de Sustentabilidade. Entretanto, a exclusão da variável tamanho da empresa coincide com os resultados encontrados por Nunes, Teixeira e Nossa (2009), Artiach, Lee, Nelson, Walker (2010), Andrade, Moreira e Pedrosa (2012) e Andrade, Bressan, Iquiapaza e Moreira (2013), em estudos similares. Assim, neste estudo não há evidência estatística que confirme que as maiores empresas são mais propensas a serem selecionadas para o Guia.

Na Tabela 2 são apresentadas as razões de chance brutas (OR $\mathrm{R}_{\text {bruto }}$ ) e razões de

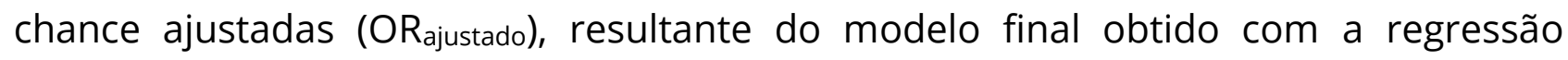
logística múltipla, e os respectivos intervalos de confiança e p-valores, representando a relação das variáveis setor de atividade, controle acionário e Índice de Sustentabilidade Empresarial com a seleção de empresas para o Guia de Sustentabilidade da Revista Exame. 
Tabela 2 - Resultados da análise de regressão logística univariada (OR bruto) e múltipla (OR $\left.\mathrm{OR}_{\text {ajustado }}\right)$

\begin{tabular}{|c|c|c|c|c|c|c|}
\hline Variáveis & ORbruto & IC 95\% & $p$-valor & $\mathrm{OR}_{\text {ajustado }}$ & IC 95\% & $\mathrm{p}$-valor \\
\hline Setor de atividade & & & & & & \\
\hline Outro & 1 & & & 1 & & \\
\hline $\begin{array}{l}\text { Recursos naturais } \\
\text { Controle acionário }\end{array}$ & 6,400 & $2,490-16,451$ & $<0,001$ & 5,109 & $1,731-15,078$ & 0,003 \\
\hline Brasileiro & 1 & & & 1 & & \\
\hline $\begin{array}{l}\text { Estrangeiro e misto } \\
\text { ISE }\end{array}$ & 2,448 & $1,064-5,631$ & 0,035 & 5,738 & $2,014-16,346$ & 0,001 \\
\hline Não & 1 & & & 1 & & \\
\hline Sim & 9,096 & $3,827-21,622$ & $<0,001$ & 9,875 & $3,377-28,874$ & $<0,001$ \\
\hline
\end{tabular}

O modelo final pode ser representado pela equação (1):

$$
P=\frac{1}{\left.1+e^{-\left(-5,387+1,631 x_{S E T}\right.}+1,747 x_{\text {CONTR }}+2,290 x_{I S E}\right)}
$$

Sendo:

$P=$ probabilidade de uma empresa ser selecionada para o Guia de Sustentabilidade da Revista Exame; $x_{S E T}=$ setor de atividade; $x_{\text {CONTR }}=$ controle acionário; $x_{I S E}=$ Índice de Sustentabilidade Empresarial; $e=$ base dos logaritmos neperianos.

De acordo com a equação, pode-se observar que a probabilidade de uma empresa ser selecionada para o Guia de Sustentabilidade da Revista Exame está associada ao setor de atividade da empresa, ao seu controle acionário e ao ISE. Assim sendo, verifica-se que as empresas de setores que utilizam diretamente recursos naturais (energia, mineração, papel e celulose, produção agropecuária, química e petroquímica e siderurgia e metalurgia) tem 5,109 vezes a chance de serem selecionadas para o Guia, em comparação com as empresas de outros setores.

Já em relação ao controle acionário, empresas controladas por estrangeiros, ou com um controle misto (brasileiro e estrangeiro) apresentam 5,738 vezes a chance de serem selecionadas como empresas modelo em sustentabilidade, em comparação com as empresas com controle nacional. Por fim, as empresas listadas no Índice de 
Sustentabilidade Empresarial apresentam 9,875 vezes a chance de serem, também, listadas no Guia de Sustentabilidade da Revista Exame.

Relativamente ao setor de atividade, o resultado encontrado está coerente com os resultados das pesquisas realizadas por Nunes, Texeira e Nossa (2009) e Andrade, Bressan, Iquiapaza e Moreira (2013). Tais autores encontraram associações significativas entre práticas de SE e o setor de atividade das empresas, mais especificamente setores considerados de alto impacto ambiental. Assim, empresas cujas atividades utilizam diretamente recursos naturais e/ou modificam o ambiente são mais propensas a desenvolver ações de RSC e SE, teriam mais chances de serem selecionadas para o Guia. Acredita-se que parte dessa associação se deva ao fato de essas empresas sofrerem maior monitoramento e pressão do mercado, governo e sociedade, em relação à responsabilidade sobre seus atos com o meio ambiente e sociedade.

Considerando o controle acionário, por meio do resultado da análise de regressão logística pode-se confirmar que as práticas de RSC e SE podem ser influenciadas pela cultura e normas ambientais do país de origem do controle. Assim sendo, os achados permitem considerar que empresas que estão em ambientes mais internacionalizados tem mais chances de serem selecionadas como empresas modelo em RSC e SE.

Por fim, com base no resultado para o ISE confirmou-se uma relação entre o fato de fazer parte deste índice e a seleção para o Guia de Sustentabilidade. Esse resultado era esperado, uma vez que ambos foram criados para elencar empresas com reconhecido comprometimento com a responsabilidade social e a sustentabilidade empresarial. Tendo em vista a principal característica da regressão logística, que é a variável resposta ser dicotômica, e o objetivo deste estudo, atribuiuse o valor 0 para representar as empresas não selecionadas para o Guia de Sustentabilidade da Revista Exame e o valor 1 para as empresas selecionadas para tal listagem. Além disso, o ponto de corte adotado no modelo foi 0,5 (valor que representa a probabilidade de um evento ocorrer pelo critério de aleatoriedade ou chances iguais (HAIR; BLACK; BABIN; ANDERSON; TATHAM, 2009), ou seja, as 
empresas que tiveram uma probabilidade estimada inferior a 0,5 foram classificadas como não pertencentes ao Guia e as que apresentaram probabilidade estimada superior a 0,5 foram classificadas como pertencentes ao Guia.

O modelo ajustado foi capaz de classificar corretamente 465 empresas que não pertencem ao Guia $(98,93 \%)$ e 2 que pertencem $(8,69 \%)$, sendo a acurácia global de classificação do modelo, dada pela média ponderada desses dois valores, igual a $94,72 \%$. Apesar de o modelo ser mais eficiente em classificar as empresas não pertencentes ao Guia de Sustentabilidade, por meio do teste de Hosmer e Lemeshow $(p$-valor $=0,275)$, da mesma forma que o percentual total de classificação, foi possível observar uma boa aderência entre os valores observados e previstos da variável resposta, indicando que o modelo pode representar a situação real de forma satisfatória.

\section{CONSIDERAÇÕES FINAIS}

O objetivo deste estudo foi verificar a relação entre o tamanho da empresa, o setor de atividade, a localização, a participação na bolsa de valores, o controle acionário, a propriedade e a participação no ISE com a seleção de empresas para o Guia da Revista Exame.

Após apresentar os conceitos teóricos sobre Responsabilidade Social Corporativa, Sustentabilidade Empresarial e Regressão Logística, foi estabelecido um modelo para estimar a probabilidade de seleção das empresas para fazerem parte do Guia. Das sete covariáveis testadas, três mostraram-se estatisticamente significativas: o setor de atividade, o controle acionário e a participação no ISE.

Assim sendo, o modelo construído permite sugerir que empresas cujas atividades utilizam diretamente recursos naturais e/ou modificam o ambiente; empresas que estão em ambientes mais internacionalizados, controladas total ou parcialmente por países estrangeiros e empresas que fazem parte do ISE tem maior probabilidade de serem selecionadas para o Guia.

Tal resultado confirma a crença de que empresas cujas atividades impactam o ambiente sofrerem uma pressão maior por parte de seus públicos em relação a uma 
postura e ações mais responsáveis e sustentáveis. Quanto ao controle acionário, pode-se indicar uma influência positiva da cultura e normas ambientais dos países de origem do controle. Por fim, conforme esperado, o resultado significativo da variável ISE permite mostrar que empresas que já possuem um histórico de atenção às questões ambientais e sociais são mais propensas a continuarem comprometidas com a responsabilidade social e a sustentabilidade empresarial.

De uma forma geral, o modelo proposto apresentou uma capacidade de previsão adequada de $94,72 \%$ dos casos e o resultado do teste de Hosmer e Lemeshow é corroborado com o resultado anterior, sugerindo uma boa aderência dos valores observados e previstos, indicando que o modelo pode representar a realidade de forma satisfatória.

Apesar das poucas comparações possíveis com outras pesquisas que investigaram determinantes que influenciam práticas de RSC e SE, acredita-se que os achados deste estudo contribuem para e ampliam o entendimento sobre as características empresariais que podem influenciar tais práticas, servindo de referência a pesquisas futuras, em relação à temática social e ambiental empresarial, e o uso da técnica de regressão logística múltipla nesta área

Destaca-se que os resultados estão sujeitos a limitações devido à base ter apenas grandes empresas e pela quantidade de informação fornecida. Assim, para ampliar os conhecimentos sobre as variáveis que influenciam as práticas de RSC e SE e a adesão a indicadores que reconhecem tais práticas, sugerem-se replicações deste estudo: com a mesma base de dados, em anos posteriores, com o objetivo de verificar se os resultados obtidos serão similares; com pequenas e médias empresas, identificando padrões de variáveis para empresas destes portes; e com empresas de setores específicos, uma vez que as características empresariais podem variar muito entre os setores de atuação existentes.

Além disso, sugere-se investigar outras variáveis que possam contribuir para determinar a propensão de empresas às práticas mencionadas e a investigação das motivações que levam as empresas ampliarem a sua atuação a investirem no social e ambiental. 


\section{REFERÊNCIAS}

ALIGLERI L, ALIGLERI L, KRUGLIANSKAS I. Gestão socioambiental: responsabilidade e sustentabilidade do negócio. São Paulo: Atlas; 2009.

ANDRADE L, BRESSAN A, IQUIAPAZA R, DE MELO MOREIRA B. Determinantes de adesão ao Índice de Sustentabilidade Empresarial da BM\&FBOVESPA e sua relação com o valor da empresa. Revista Brasileira de Finanças. 2013;11(2):181-213.

ANDRADE L, MOREIRA B, PEDROSA G. Determinantes da performance de sustentabilidade empresarial: uma nova análise sobre as empresas brasileiras de capital aberto. XXVI Encontro da Associação Nacional de Pós-Graduação e Pesquisa em Administração; 2012 September 22-26; Rio de Janeiro; RJ; 2012.

ARAÚJO G, BUENO M, SOUSA A, MENDONÇA P. Sustentabilidade empresarial: conceito e indicadores. III Congresso Virtual Brasileiro de Administração; 2006 November 24-26; 2006.

ARTIACH T, LEE D, NELSON D, WALKER J. The determinants of corporate sustainability performance. Accounting \& Finance. 2010;50(1):31-51.

BOAVENTURA JMG, CARDOSO FR, SILVA ES, SILVA RS. Teoria dos Stakeholders e Teoria da Firma: um estudo sobre a hierarquização das funções-objetivo em empresas brasileiras. Revista Brasileira de Gestão de Negócios. 2009;11(32):289-307.

BOLSA DE VALORES, MERCADORIAS E FUTUROS [Internet]. BM\&FBOVESPA. [cited 2013 oct 17]. Brasil Bolsa Balcão: Available from: http:// www.bmfbovespa.com.br/home.aspx?idioma=pt-br.

BRAGA J, OLIVEIRA J, SALOTTI B. Determinantes do nível de divulgação ambiental nas demonstrações contábeis de empresas brasileiras. Revista de Contabilidade da UFBA. 2010;3(3):81-95.

BUENO MP, SALVADOR N. Sustentabilidade das práticas de gestão empresarial de duas usinas de açúcar e álcool de cana-de-açúcar no estado de São Paulo. VII Congreso de Medio Ambiente; 2012 May 22-24; La Plata, Argentina; 2012.

CALDELLI A, PARMIGIANI M. Management information system-a tool for corporate sustainability. Journal of Business Ethics. 2004;52(2):159-171.

CAMPBELL A. Stakeholders: The case in favor long range planning. Great Britain. 1997;30(3):446-450.

CARROLL A. A three-dimensional conceptual model of corporate social performance. Academy of Management Review. 1979, 4(4):497-505. 
COASE R. The nature of the firm. Economica. 1937;4(16):386-405.

CONFALONIERI U, MARINHO D. Mudança climática global e saúde: perspectivas para o Brasil. Revista Multiciência. 2007;8:48-64.

DIERKES M, PRESTON L. Corporate social accounting reporting for the physical environment: A critical review and implementation proposal. Accounting, Organizations and society. 1977;2(1):3-22.

DONALDSON T, PRESTON L. The stakeholder theory of the corporation: Concepts, evidence, and implications. Academy of management Review. 1995;20(1):65-91.

ELKINGTON J. Partnerships from cannibals with forks: The triple bottom line of 21stcentury business. Environmental quality management. 1998;8:37-51.

GOLDNER N, TEIXEIRA A, NOSSA V, GALDI C. Análise das variáveis que influenciam a adesão das empresas ao índice BM\&F Bovespa de sustentabilidade empresarial. Base - Revista de Administração e Contabilidade da UNISINOS. 2010; 7(4):328-340.

GONZALEZ MHG, ANDRADE DC. A sustentabilidade ecológica do consumo em Minas Gerais: uma aplicação do método da pegada ecológica. Nova economia. 2015;25:421446.

HAIR J, BLACK W, BABIN B, ANDERSON R, TATHAM R. Análise multivariada de dados. Porto Alegre: Bookman Editora; 2009.

HOSMER JDW, LEMESHOW S. Applied Logistic Regression. New York: John Wiley; 1989.

IRIGARAY H, VERGARA S, ARAÚJO R. Responsabilidade Social Corporativa: o que revelam os relatórios sociais das empresas. Organizações \& Sociedade. 2017;24(80):73-88.

MACEDO M, SOUSA A, SOUSA, A. Desempenho de empresas socialmente responsáveis: uma análise por índices contábil-financeiros. Revista Produção Online. 2008;7(4).

MACHADO FILHO CAP, ZYLBERSZTAJN D. A empresa socialmente responsável: O debate e as implicações. Revista de Administração. 2004;39(3):242-254.

MARREWIJK, MV. Concepts and definitions of CSR and corporate sustainability: Between agency and communion. Journal of business ethics. 2003;44(2):95-105.

MCWILLIAMS A, SIEGEL D. Corporate social responsibility and financial performance: correlation or misspecification? Strategic management journal. 2000;21(5):603-609. 
MELO NFP, FROES C. Gestão da responsabilidade social corporativa: o caso brasileiro: da filantropia tradicional à filantropia de alto rendimento e ao empreendedorismo social. Rio de Janeiro: Qualitymark; 2001.

NETO AS. A reação dos preços das ações à divulgação dos resultados contábeis: evidências empíricas sobre a capacidade informacional da contabilidade no mercado brasileiro. [dissertation]. Vitória: Fundação Instituto Capixaba de Pesquisas em Contabilidade, Economia e Finanças/FUCAPE; 2004. 243 p.

NUNES J, TEXEIRA A, NOSSA V. Análise variáveis que infuenciam a adesão das empresas ao índice Bovespa de sustentabilidade empresarial. XXXIII Encontro da Associação Nacional de Pós-Graduação e Pesquisa em Administração; 2009; September 19-23; São Paulo; SP; 2009.

OLIVEIRA DM, ALMEIDA CAS, ROCHA LA, TORTATO U, SILVA WV. Relação entre responsabilidade social corporativa e desempenho financeiro das empresas brasileiras do setor energético. Revista Uniabeu. 2015;8:17-32.

OLIVEIRA GT, SILVA RM, CARDOSO, AP, OLIVEIRA MS, CASTRO RM, PINTO AJA. Sustentabilidade como vantagem competitiva nas organizações: um levantamento da responsabilidade das empresas. Revista Brasileira de Administração Científica. 2018;9(1):127-136.

REZENDE I, SANTOS L. Análise da rentabilidade e performance dos investimentos socialmente responsáveis: um estudo empírico no mercado brasileiro. $3^{\circ}$ Encontro da Associação Nacional de Pós-Graduação e Pesquisa em Administração; 2006; September 23-27; Salvador, BA; 2006.

SILVEIRA A, YOSHINAGA C, BORBA P. Crítica à teoria dos stakeholders como funçãoobjetivo corporativa. Revista de Gestão. 2005;12(1):33-42.

SOARES B, NAVARRO M, FERREIRA A. Desenvolvimento sustentado e consciência ambiental: natureza, sociedade e racionalidade. Ciências \& Cognição. 2004;2:42-49.

TENÓRIO O. Responsabilidade social empresarial: teoria e prática. Rio de Janeiro: FGV; 2015.

VALLANI C, RIBEIRÃO, M. A sustentabilidade e a contabilidade. Simpósio de Administração da Produção, Logística e Operações Internacionais; 2006 São Paulo, SP; 2006.

VEIGA J. Indicadores de sustentabilidade. Estudos avançados. 2010;24(68):39-52. 
WAJNBERG D, LEMME C. Exame da divulgação do relacionamento entre iniciativas socioambientais e desempenho financeiro corporativo nos bancos brasileiros. Revista de Gestão Social e Ambiental. 2009;3:53-69. 